\title{
Research on deepwater synthetic drilling fluid and its low temperature rheological properties
}

\author{
Hu Youlin ${ }^{1 *}$, Yue Qiansheng ${ }^{1}$, Liu Shujie ${ }^{2}$, Fu Zaiguo ${ }^{1}$ and Liang Shan ${ }^{3}$ \\ ${ }^{1}$ College of Petroleum Engineering, Yangtze University, Jingzhou, Hubei 434023, China \\ ${ }^{2}$ CNOOC Research Institute, Beijing 100027, China \\ ${ }^{3}$ Shanghai Shenkai Petroleum Equipment Corporation Ltd, Shanghai 201114, China \\ (C) China University of Petroleum (Beijing) and Springer-Verlag Berlin Heidelberg 2011
}

\begin{abstract}
With the rapid development of deepwater drilling operations, more and more complex technical challenges have to be faced due to the rigorous conditions encountered. One of these challenges is that the drilling fluid used must had good rheological properties at low temperatures and high ability to inhibit hydrate formation. Synthetic drilling fluid has been widely applied to deepwater drilling operations due to its high penetration rate, excellent rheological properties, good ability to prevent hydrate formation, and high biodegradability. A synthetic drilling fluid formulation was developed in our laboratory. The rheological properties of this drilling fluid at low temperatures $\left(0-20{ }^{\circ} \mathrm{C}\right)$ were tested with a 6 -speed viscometer and its ability to inhibit hydrate formation was evaluated at $20 \mathrm{MPa} \mathrm{CH}_{4}$ gas and $0{ }^{\circ} \mathrm{C}$ by differential scanning calorimetry (DSC). Several factors influencing the low temperature rheological properties of this synthetic drilling fluid were studied in this paper. These included the viscosity of the base fluid, the amount of CEMU and organic clay, and the water volume fraction.
\end{abstract}

Key words: Deepwater drilling, synthetic drilling fluid, low temperature rheological properties, gas hydrate

\section{Introduction}

There are abundant oil and gas resources in deepwater areas, and deepwater oil and gas exploration has expanded greatly over the years. Drilling fluid plays a key role in all deepwater drilling operations, and its low temperature rheological properties and gas hydrate formation in the fluid brings severe challenge to deepwater drilling fluid technology. The temperature changes during deepwater drilling operations greatly influences the rheological properties of drilling fluids; especially it is difficult to control the yield point and viscosity of drilling fluids. This can initiate lost circulation, high equivalent circulating density (ECD), and increasing difficulty of pressure control (Cameron, 2000; Zamora et al, 2000; Herzhaft et al, 2001; Amanullah and Boyle, 2006; Korloo, 2007; Xu et al, 2008; Wang et al, 2009; Smith et al, 2010; Yue et al, 2011). Once formed in the deepwater drilling fluid, gas hydrates can plug the wellbore, annular space or blowout preventer, thus leading to accidents, extending the operation cycle, and increasing operation cost. Meanwhile, the decomposition of gas hydrates also brings about serious problems such as wellbore instability, lost circulation, and blowout. During deepwater drilling, the formation of

* Corresponding author. email: 61872218@qq.com

Received August 29, 2010 gas hydrates is not only an economic issue but also more importantly a safety issue (Hu and Liu, 2008).

Synthetic drilling fluid is widely used in offshore oil and gas drilling due to its high penetration rate and high biodegradability. However, the apparent viscosity and yield point of conventional synthetic drilling fluid increases significantly with a decrease in temperature in deepwater drilling operations. It is difficult to control the pressure fluctuations associated with conventional synthetic drilling fluid and then downhole lost circulation often occurs during drilling, tripping drill pipe, running casing and cementing. Based on conventional synthetic drilling fluid, a new synthetic drilling fluid, which has constant rheological properties and is suitable for deepwater drilling, was developed by optimizing and modifying treatment agents. The difference between the newly-developed synthetic drilling fluid and conventional synthetic drilling fluid is that the newly-developed synthetic drilling fluid exhibits near constant rheological properties over a wide temperature range, i.e. some key rheological parameters of the new synthetic drilling fluid, such as the yield point, the $6 \& 3 \mathrm{rpm}$ readings were nearly independent of temperature and remained stable over a wide temperature range. The new synthetic drilling fluid overcomes technical problems met by conventional synthetic drilling fluid during deepwater drilling (Zevallos et al, 1996; Jenkins et al, 2003; Van Oort et al, 2004; Rojas et al, 2007; Vajargah et al, 2009; Gandleman et al, 2007; Geng et al, 2010). 
2 Properties of the synthetic drilling fluid for deepwater drilling

\subsection{Optimization of basic formulation and basic properties}

A synthetic drilling fluid formulation was developed in the laboratory for deepwater offshore drilling. This drilling fluid was formulated from linear alpha olefin $\left(\mathrm{CH}_{3}\left(\mathrm{CH}_{2}\right)_{12} \mathrm{CH}=\mathrm{CH}_{2}\right)+\mathrm{CaCl}_{2}$ solution (concentration $20 w t \%)+3 \%(w t / v o l)$ CEMU (compound emulsifier containing calcium phytate and an amide surfactant) $+3 \%(\mathrm{wt} /$ vol) organic clay $+3 \%(\mathrm{wt} / \mathrm{vol}) \mathrm{HiFLO}$ (sulfonated asphalt, a filtrate reducer $)+2 \%(\mathrm{wt} / \mathrm{vol}) \mathrm{CaO}+30 \%(\mathrm{wt} / \mathrm{vol})$ barite. In this formulation, the volume ratio of linear alpha olefin to $\mathrm{CaCl}_{2}$ solution is $80: 20$. The organic clay was prepared by changing the inorganic cation of sodium bentonite with quaternary ammonium cation.

This synthetic drilling fluid was prepared as follows: CEMU was added in the linear alpha olefin under stirring at a rate of $8,000 \mathrm{r} / \mathrm{min}$. After fully stirring the mixture, $20 \mathrm{wt} \% \mathrm{CaCl}_{2}$ solution was added. After stirring for 10 min, the organic clay, HiFLO, and $\mathrm{CaO}$ were added. After continuously stirring for $10 \mathrm{~min}$, barite was added to adjust the fluid density to $1.15 \mathrm{~g} / \mathrm{cm}^{3}$ and then the synthetic drilling fluid was stirred for $20 \mathrm{~min}$. The rheological properties, filter loss, and electric stability of the synthetic drilling fluid were measured following the standard procedures (GB/T 167821997, China) and listed in Table 1. High temperature/high pressure (HTHP) filtration tests were performed at $100^{\circ} \mathrm{C}$ and $3.5 \mathrm{MPa}$.

Table 1 The basic properties of the newly-developed synthetic drilling fluid for deepwater drilling

\begin{tabular}{|c|c|c|c|c|c|c|c|c|c|}
\hline $\begin{array}{l}\text { Experimental } \\
\text { conditions }\end{array}$ & $\begin{array}{l}\text { Density } \\
\mathrm{g} / \mathrm{cm}^{3}\end{array}$ & $\begin{array}{l}\text { Apparent viscosity } \\
\mathrm{mPa} \cdot \mathrm{s}\end{array}$ & $\begin{array}{c}\text { Plastic viscosity } \\
\mathrm{mPa} \cdot \mathrm{s}\end{array}$ & $\begin{array}{l}\text { Yield point } \\
\mathrm{Pa}\end{array}$ & $\Phi 6 / Ф 3$ & $\begin{array}{c}\text { Electric } \\
\text { stability } \\
\text { V }\end{array}$ & $\begin{array}{c}\text { Gel strength } \\
10^{\prime \prime} / 10^{\prime} \\
\mathrm{Pa}\end{array}$ & $\begin{array}{l}\text { API filtrate } \\
\mathrm{mL} / 30 \mathrm{~min}\end{array}$ & $\begin{array}{l}\text { HTHP filtrate } \\
\mathrm{mL} / 30 \mathrm{~min}\end{array}$ \\
\hline Room temperature & 1.15 & 31 & 23 & 8 & $5 / 4$ & 589 & $2 / 4$ & 0.4 & - \\
\hline After aging at $100^{\circ} \mathrm{C}$ for $16 \mathrm{~h}$ & 1.15 & 34 & 28 & 6 & $4 / 3$ & 676 & $1.5 / 4$ & 0.4 & 3.0 \\
\hline
\end{tabular}

\subsection{Low-temperature rheological properties}

The apparent viscosity and yield point of a drilling fluid increase significantly with a decrease in temperature, and finally gelling occurs. The rheological properties of the synthetic drilling fluid were measured at low temperatures $\left(0,4,10,15,20^{\circ} \mathrm{C}\right.$, respectively) with a viscometer and the experimental results are listed in Table 2 . The results showed that the drilling fluid viscosity increased with a decrease in temperature when the temperature was lower than $20^{\circ} \mathrm{C}$, but the $6 \& 3 \mathrm{rpm}$ readings and the yield point of the drilling fluid were nearly independent of temperature.

Table 2 Rheological properties of the synthetic drilling fluid at low temperatures

\begin{tabular}{ccccc}
\hline Temperature, ${ }^{\circ} \mathrm{C}$ & Apparent viscosity, mPa·s & Plastic viscosity, mPa·s & Yield point, Pa & $\Phi 6 / \Phi 3$ \\
\hline 20 & 34 & 28 & 6 & $4 / 3$ \\
15 & 39 & 33 & 6 & $4 / 3$ \\
10 & 43 & 37 & 6 & $4 / 3$ \\
4 & 47 & 41 & 6 & $4 / 3$ \\
0 & 50.5 & 44 & 6.5 & $4 / 3$ \\
\hline
\end{tabular}

\subsection{Inhibition of gas hydrate formation}

Once gas hydrate forms in the drilling fluid, it can plug the wellbore, annulus, and blowout preventers, thus causing accidents, extending the operating cycle and increasing operation cost. Differential scanning calorimetry (DSC) is a rapid and sensitive technique, broadly used for the characterization of any kind of phase change. In this study, DSC was used to investigate whether gas hydrate had formed in the deepwater drilling fluid. This method was unaffected by the density, viscosity and the solids of drilling fluid. The main principle of DSC is: the gas hydrate releases heat during decomposition into gas (Wang et al, 2008). A HP-micro DSC VII was used to study whether gas hydrate forms in the synthetic drilling fluid at low temperature. In this experiment, $\mathrm{CH}_{4}$ was used as the guest molecule for forming a gas hydrate. Detailed procedures were as follows: 1) $10 \mathrm{mg}$ of the synthetic drilling fluid was added into a sample channel. 2) The pressure was increased to $20 \mathrm{MPa}$ by injection $\mathrm{CH}_{4}$ into the sample channel. 3) The synthetic drilling fluid was quickly cooled to $0{ }^{\circ} \mathrm{C}$ and kept for 5 hours. 4) Then the fluid was slowly heated to $20^{\circ} \mathrm{C}$ at a constant rate of $0.5^{\circ} \mathrm{C} /$ $\mathrm{min}$. The process was tested whether there is an endothermic peak. Fig. 1 shows that no endothermic peak was observed in the heat flow curve of the synthetic drilling fluid during the temperature increase. This indicates that no gas hydrate formed in the synthetic drilling fluid at $20 \mathrm{MPa} \mathrm{CH}_{4}$ and $0{ }^{\circ} \mathrm{C}$. 


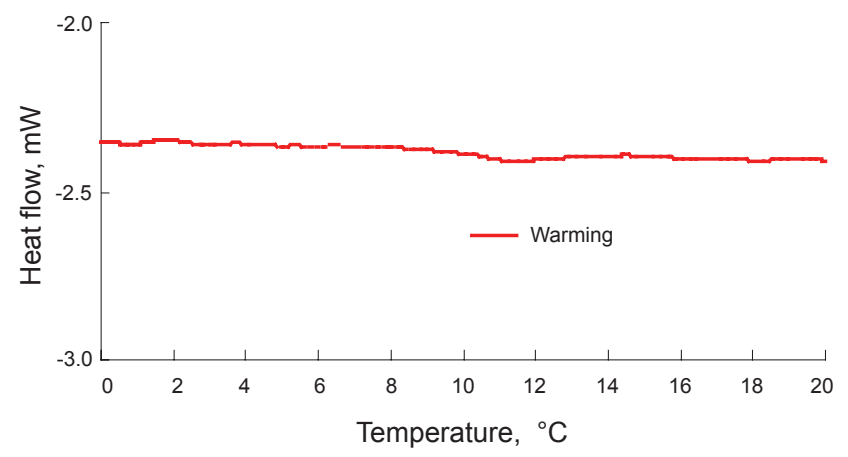

Fig. 1 Heat flow curve of the synthetic drilling fluid

\section{Factors influencing the low temperature rheological properties of the drilling fluid}

Factors governing rheological properties of the synthetic drilling fluid include the viscosity of the base fluid, emulsifier and organic clay contents, the volume ratio of continuous and dispersed phase (i.e. linear alpha olefin and water), the size and distribution of dispersed phase droplets, the characteristics and electric properties of interfacial film of emulsifier, the temperature and the pressure (Ghalambor et al, 2008). Based on the optimized deepwater synthetic drilling fluid formation, the influences of the viscosity of the base fluid, CEMU and organic clay contents, the water volume fraction on the rheological properties of the deepwater synthetic drilling fluid were investigated.

\subsection{Effect of the viscosity of the base fluid}

The linear alpha olefin and SYN-2 (a fatty acid ester, $\left.\mathrm{CH}_{3}\left(\mathrm{CH}_{2}\right)_{m} \mathrm{COO}\left(\mathrm{CH}_{2}\right)_{n} \mathrm{CH}_{3}\right)$ had a viscosity of 3.5 and 7 $\mathrm{mPa} \cdot \mathrm{s}$ respectively at $20{ }^{\circ} \mathrm{C}$, but 5 and $12 \mathrm{mPa} \cdot \mathrm{s}$ at $4{ }^{\circ} \mathrm{C}$. According to the formulation of the synthetic drilling fluid, the linear alpha olefin and SYN-2 were selected as the base fluid for studying the rheological properties of synthetic drilling fluids at low temperatures, and experimental results were shown in Figs. 2 and 3. The apparent viscosity of the drilling fluid containing SYN-2 increased more significantly than that of the drilling fluid containing linear alpha olefin. The viscosity of the base fluid influenced the apparent viscosity of the drilling fluid at low temperatures. For both drilling fluids, the variations of the yield points of drilling fluids at low temperatures were basically identical;

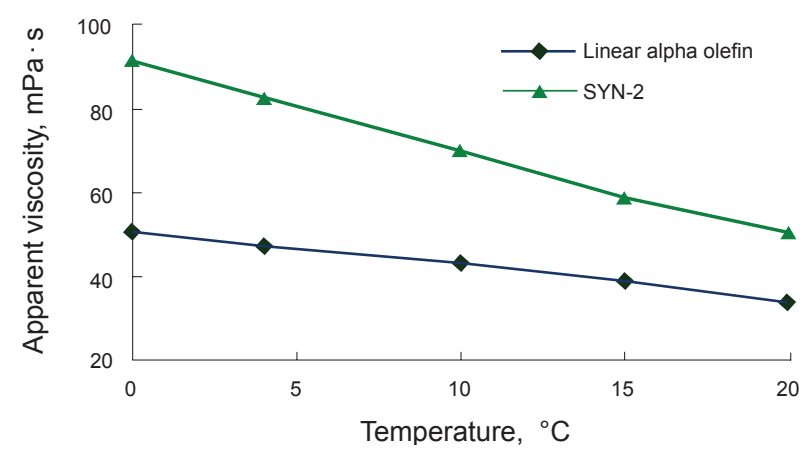

Fig. 2 The influence of the viscosity of the base fluid on the apparent viscosity-temperature curves of synthetic drilling fluids

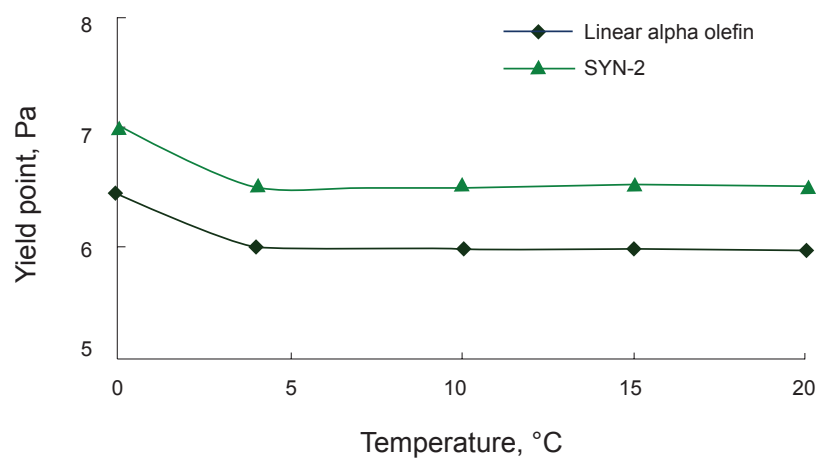

Fig. 3 The influence of the viscosity of the base fluid on the yield point-temperature curves of synthetic drilling fluids

the viscosity of the base fluid had little effect on the low temperature yield point of the drilling fluid. A base fluid with a low viscosity was recommended for use in deepwater drilling (Burrows et al, 2001).

\subsection{Effect of the addition amount of CEMU}

Based on the optimized deepwater synthetic drilling fluid formulation, the influence of CEMU content on the low temperature rheological properties of drilling fluids was studied. The amounts of CEMU added in the drilling fluids were $3 \%, 4 \%$, and $5 \%$, respectively. The experimental results were shown in Figs. 4 and 5. With the content of CEMU increasing, the apparent viscosity and the yield point of the drilling fluid changed significantly with temperature when the content of CEMU was high (e.g. 5\%). When the CEMU content in the drilling fluid was $3 \%$, the curve of apparent viscosity-temperature was relatively flat, and the yield point basically remained stable. The CEMU content influenced the size and distribution of the dispersed phase droplets. With an increase in the CEMU content, the average particle size of the dispersed droplets decreased, thus the interaction between the interfacial area and dispersed droplets strengthened, and the interaction between the dispersed and continuous phases increased. The increase in the CEMU content of the drilling fluid was beneficial to forming an interfacial film of high mechanical strength. The interfacial film properties and dispersed phase particle size influenced the apparent viscosity and yield point of the synthetic drilling fluid at low temperatures.

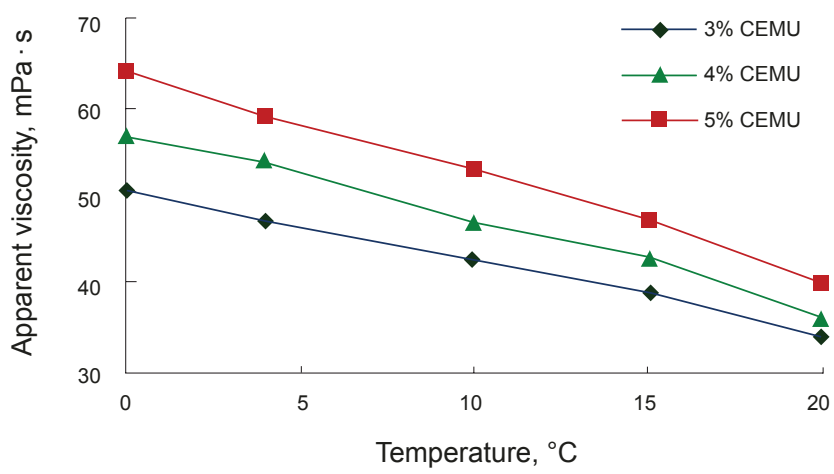

Fig. 4 The amount of CEMU influences the apparent viscosity-temperature curves of synthetic drilling fluids 


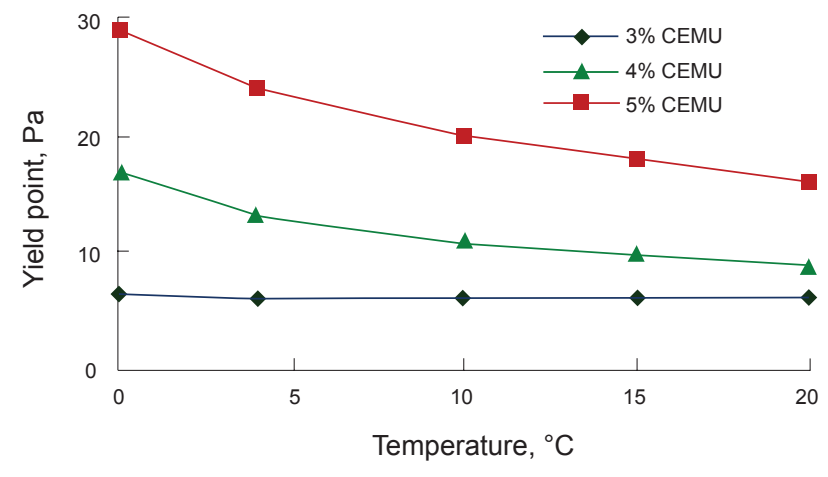

Fig. 5 The amount of CEMU influences the yield point-temperature curves of synthetic drilling fluids

\subsection{Effect of the addition amount of organic clay}

Figs. 6 and 7 show the influence of the content of organic clay on rheological properties of the synthetic drilling fluid at low temperatures. The amount of organic clay added was fixed at $3 \%, 4 \%$, and $5 \%$, respectively. Figs. 6 and 7 indicate that the apparent viscosity and the yield point of the drilling fluid changed significantly with temperature when the content of organic clay was high (e.g. $5 \%$ ). There was some affinity between the organic clay and water drops, some micro water drops would be adsorbed on the surface of organic clay spontaneously and wetted part of clay. The interaction between organic clay and micro water drops increased with the amount of organic clay, especially at low temperatures. This was due to the formation of card-house structure between organic clay and water drops, which had higher structure strength at lower temperatures.

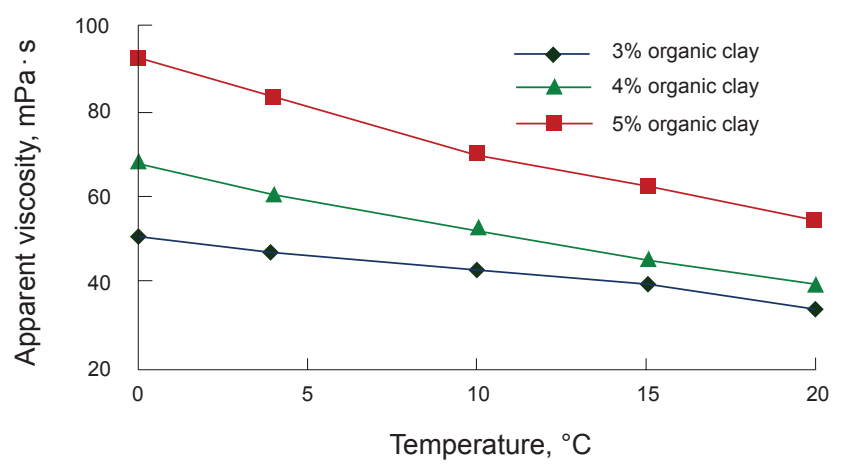

Fig. 6 The influence of organic clay on the apparent viscosity-temperature curves of synthetic drilling fluids

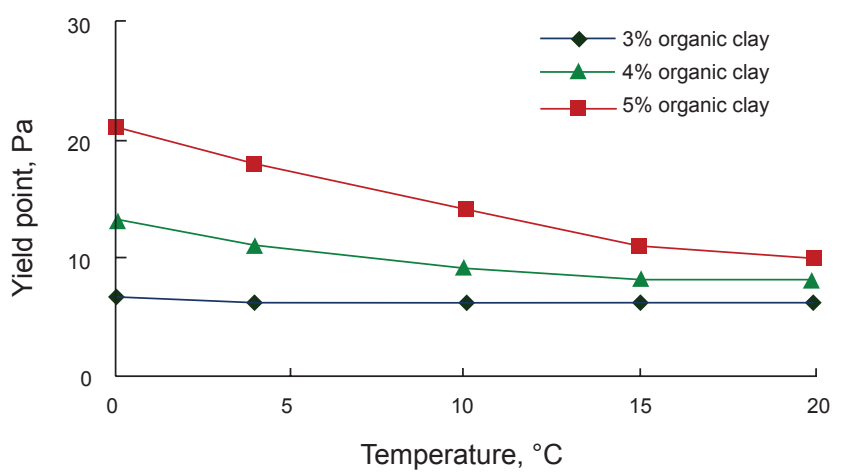

Fig. 7 The influence of organic clay on the yield point-temperature curves of synthetic drilling fluids

\subsection{Effect of the water volume fraction}

With the linear alpha olefin as the continuous phase and water as the dispersed phase, small water droplets are generated in the continuous phase (linear alpha olefin), therefore the water volume fraction also influences the low temperature rheological properties of the synthetic drilling fluid. Experimental results were shown in Figs. 8 and 9. In these experiments the water volume fraction was $20 \%$, $30 \%$, and $40 \%$. The apparent viscosity and yield point of the drilling fluid changed significantly with temperature when the water volume fraction was high (e.g. $40 \%$ ). With the volume fraction of water phase increasing in the drilling fluid, the number of dispersed droplets (i.e. water droplets) increased in the continuous phase, and then the distance between the water droplets decreased rapidly. Therefore, the interaction force among water droplets increased due to their collisions or relative sliding, leading to aggregation of water droplets and subsequent formation of complex structure aggregates. The increase in the water volume fraction increased the numbers of water droplets in the continuous phase and then their aggregation. The aggregation rate increased as the temperature decreased. With the volume fraction of water phase increasing, the water droplet content increased. The strength of card-house structure formed by the interaction of organic clay with water droplets increased. The structural strength was higher at lower temperatures.

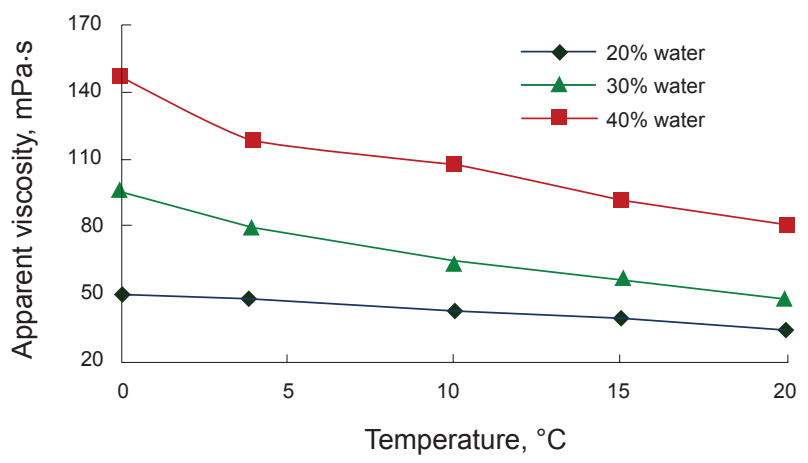

Fig. 8 The influence of water volume fraction on the apparent viscosity-temperature curves of synthetic drilling fluids

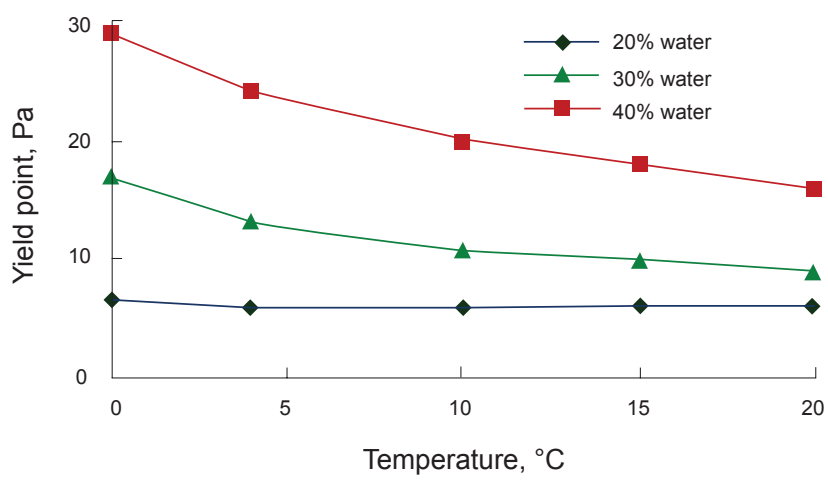

Fig. 9 The influence of water volume fraction on the yield point-temperature curves of synthetic drilling fluids 


\section{Conclusions}

1) The optimized synthetic drilling fluid had excellent rheological properties at low temperatures and gas hydrate did not form in the drilling fluid at $20 \mathrm{MPa}$ and $0{ }^{\circ} \mathrm{C}$. This optimized synthetic drilling fluid could be applied to deepwater drilling.

2) The base fluid viscosity, the amounts of emulsifier and organic clay, and the water volume fraction influenced the low temperature rheological properties of the synthetic drilling fluid. Linear alpha olefin of low viscosity was used as the base fluid in the synthetic drilling fluid.

\section{Acknowledgements}

The authors are grateful for the financial support from the National Science and Technology Key Projects (2008ZX05056-002-03-04 and 2008ZX05030-005-07-03).

\section{References}

Amanullah M and Boyle R A. Multifunctional gel system to mitigate deepwater drilling challenges. Paper SPE 104080 presented at the 2006 International Oil \& Gas Conference and Exhibition held in Beijing, China, 5-7 December 2006

Burrows K, Evans J, Hall J, et al. New low viscosity ester is suitable for drilling fluids in deepwater applications. Paper SPE 66553 presented at the SPE/EPA/DOE Exploration and Production Environmental Conference held in San Antonio, Texas, U.S.A., 26-28 February 2001

Cameron C B. Drilling fluids design and field procedures to meet the ultra deepwater drilling challenge. Paper SPE 66061 presented at the 24th SPE Nigeria Annual Technical Conference and Exhibition held in Abuja, Nigeria, 7-9 August 2000

Gandleman R A, Leaf R A F, Goncalves J T, et al. Synthetic-based drilling fluid with study on gelation and freezing phenomena of synthetic drilling fluids in ultradeepwater environments. Paper SPE/ IADC 105881 presented at the 2007 SPE/IADC Drilling Conference held in Amsterdam, The Netherlands, 22-22 February 2007

Geng J J, Yan J N, Li H K, et al. Synthetic-based drilling fluid with constant-rheology used in deepwater drilling. Petroleum Drilling Techniques. 2010. 38(2): 91-94 (in Chinese)

Ghalambor A, Ashrafizadeh S N and Nasiri M. Effect of basic parameters on the viscosity of synthetic-based drilling fluids. Paper SPE 112276 presented at the 2008 SPE International Symposium and Exhibition on Formation Damage Control held in Lafayette, Louisiana, U.S.A., 13-15 February 2008

Herzhaft B, Peysson Y, Isambourg P, et al. Rheological properties of drilling muds in deep offshore conditions. Paper SPE/IADC 67736 presented at the SPE/IADC Drilling Conference held in Amsterdam, The Netherlands, 27 February-1 March 2001

$\mathrm{Hu}$ Y L and Liu H. Effects of natural gas hydrates on deepwater drilling fluid and control measures. Natural Gas Industry. 2008. 28(11): 68-70 (in Chinese)

Jenkins R W, Schmidt D A, Stokes D, et al. Drilling the first ultra deepwater wells offshore Malaysia. Paper SPE 79807 presented at the SPE/IADC Drilling Conference held in Amsterdam the Netherlands, 19-21 February 2003

Korloo J. Indonesia deepwater field development technical, contracting, and execution challenges. Paper SPE 109137 presented at the 2007 Asia Pacific Oil \& Gas Conference and Exhibition held in Jakarta, Indonesia, 30 October-1 November 2007

Rojas J C, Bern P, Plutt L J, et al. New constant-rheology synthetic-based fluid reduces downhole losses in deepwater environments. Paper SPE 109586 presented at the SPE Annual Technical Conference and Exhibition held in Anahelm, California U.S.A., 11-14 November 2007

Smith D, Winters W, Tarr B, et al. Deepwater riserless mud return system for dual gradient tophole drilling. Paper SPE 130308 presented at the 2010 SPE/IADC Managed Pressure and Underbalanced Operations Conference and Exhibition held in Kuala Lumpur, Malaysia, 24-25 February 2010

Vajargah A K, Tahmasbi K and Arsanjani N. The feasibility study of replacing oil based mud with more environmentally acceptable paraffin based system in Iranian Oil Fields. Paper SPE 123519 presented at the 2009 SPE Pacific Health, Safety, Security, and Environment Conference and Exhibition held in Jakarta, Indonesia, 4-6 August 2009

Van Oort E, Friedheim J and Toups B. New flat-rheology synthetic-based for improved deepwater drilling. Paper SPE 90987 presented at the SPE Annual Technical Conference and Exhibition held in Houston, Texas, U.S.A., 26-29 September 2004

Wang Q S, Feng K M, Li J, et al. Evaluation of gas hydrate inhibition in deepwater drilling fluid based on high pressure microcalorimetry. Drilling \& Production Technology. 2008. 30(2): 41-44 (in Chinese)

Wang S, Song M Q and Liu E P. Development of foreign deepwater drilling fluid. Petroleum Drilling Techniques. 2009. 37(3): 8-12 (in Chinese)

Xu J F, Qiu Z S and Lv K H. Studies of deepwater drilling fluid. Drilling Fluid and Completion Fluid. 2008. 25(5): 9-10 (in Chinese)

Yue Q S, Liu S J, He B S, et al. Rheological properties of the synthetic drilling fluid in deep-water drilling conditions. Acta Petrolei Sinica. 2011. 32(1): 145-147 (in Chinese)

Zamora M, Broussard P N and Stephens M P. The top 10 mud-related concerns in deepwater drilling operations. Paper SPE 59019 presented at the 2000 SPE International Petroleum Conference and Exhibition held in Villahermosa, Mexico, 1-3 February 2000

Zevallos M A L, Candler J, Wood J H, et al. Synthetic based fluids enhance environmental and drilling performance in deepwater locations. Paper SPE 35329 presented at the SPE lnternational Petroleum Conference \& Exhibition of Mexico held in Villahermosa, Tabasco, Mexico, 5-7 March 1996

(Edited by Sun Yanhua) 